\title{
ESCRITURA LOCAL: LA NOCIÓN DE “CIENCIA" EN LA OBRA DE EZEQUIEL ROJAS
}

\author{
Carlos Arturo López Jiménez* \\ doi:10.11144/Javeriana.uph32-65.elnc
}

\begin{abstract}
RESUMEN
Ezequiel Rojas es reconocido como uno de los más importantes pensadores utilitaristas colombianos del siglo XIX. No obstante, sus escritos han sido ignorados o subestimados por los historiadores de la filosofía en Colombia debido a que están más interesados en leerlos a la luz de la historia de la filosofía europea, de los conflictos de clase o de los asuntos partidistas, que desde la importancia de las formas locales de escritura. Para enfrentar esta situación, el presente escrito es una reflexión sobre la noción "ciencia" en la obra de Ezequiel Rojas que enfatiza el "ejercicio de escribir" como práctica concreta con ritmos propios. Así, se busca obtener una visión panorámica de la obra de este autor y de una parte de la historia de la filosofía en Colombia.
\end{abstract}

Palabras clave: Ezequiel Rojas; filosofía en Colombia; siglo XIX; utilitarismo; ejercicio de escribir

* Universidad Libre de Berlín, Berlín, Alemania.

Correo electrónico: carlosarturolopezj@yahoo.es

Para citar este artículo: López Jiménez, C.A. (2015). Escritura local: La noción de "ciencia" en la obra de Ezequiel Rojas. Universitas Philosophica, 32(65), pp. 159-190. ISSN 0120-5323, ISSN en línea: 2346-2426, doi:10.11144/ Javeriana.uph32-65.elnc 


\title{
LOCAL WRITING: THE NOTION OF “SCIENCE” IN EZEQUIEL ROJAS' WORK
}

\author{
Carlos Arturo López Jiménez
}

\begin{abstract}
Ezequiel Rojas is recognized as one of the most important Colombian utilitarian thinkers of the nineteenth century. His writings, however, have been ignored or underestimated by philosophy historians in Colombia who read them from the perspective of European history of philosophy, class struggles or partisan issues - a reading which ignores the manner of local writings. The present text offers instead a reflection on the notion of "science" in Rojas' philosophical works emphasizing the practice of localized "exercise of writing" (ejercicio de escribir), and thus provides a comprehensive view of his works as part of Colombian history of philosophy. Key words: Ezequiel Rojas; Colombian philosophy; 19th century; utilitarianism; exercise of writing
\end{abstract}


Cuestiones generales

\section{La poca ATENCión prestada a los escritos filosóficos de Ezequiel Rojas} (1804-1873) resulta extraña, pues suele reconocérsele como maestro de la generación de los liberales radicales colombianos ${ }^{1}$ (Quintana, 2006, pp. 11-37), y el más destacado representante del benthamismo que hubo en este país (Jaramillo Uribe, 2001, p. 298). ${ }^{2}$ Tal extrañeza se confirma si se compara con el interés que despiertan los trabajos de Miguel Antonio Caro (el último y tal vez el más férreo opositor que tuvo Rojas). ${ }^{3}$ Aunque la falta de interés generalizado en el estudio de la producción filosófica colombiana es una probable explicación de esa insuficiente atención ${ }^{4}$, tal vez los dictámenes desfavorables que algunos investigadores colombianos han hecho sobre sus escritos, sean más decisivos en este olvido. Por ejemplo, Carlos Valderrama Andrade ha dicho que "el simplismo científico y el

1 Nombre con el que se identifica a las élites liberales que se mantuvieron en los principales cargos del gobierno a comienzos de la segunda mitad del siglo XIX en el actual territorio colombiano. Este grupo suele vincularse con las importantes transformaciones sociales y políticas conocidas como las Reformas de mitad de siglo, las cuales, por lo regular, son entendidas como una puesta al día del país en los principios democráticos del capitalismo y del liberalismo internacional entre los años 1849-1953, aproximadamente.

2 "En pos de Rojas se configuró todo un grupo de discípulos, que brillaron todos con luz propia: José María Rojas Garrido, Manuel Murillo Toro, Enrique Camacho, Salvador Camacho Roldán, Juan Manuel Rudas, Francisco Eustaquio Álvarez, Alejandro Agudelo, Ángel María Galán, para citar a los más destacados" (Valderrama Andrade, 1989, p. 122).

3 Puede leerse sobre la importancia de este autor en una reseña del libro de Rafael Rubiano Muñoz titulado Prensa y tradición, donde se afirma que este libro “(...) inaugura en la década que comienza, las publicaciones sobre el pensador bogotano del siglo XIX Miguel Antonio Caro. Hablo de decenios porque una rápida revisión bibliográfica mostraría que al menos cada década luego de 1909 -año del deceso de Caro- se publica siquiera un libro o un artículo importante sobre este personaje" (López J., 2011, p. 71). A propósito de la polémica entre Caro y Rojas, y más exactamente entre Caro y el benthamismo, Carlos Valderrama Andrade (1989) publicó un artículo titulado "Relación polémica de Miguel Antonio Caro con el Benthamismo".

4 No obstante, ya pueden encontrarse, desde diversas áreas, estudios de la filosofía en Colombia, no solo de los procesos sociales en los que se involucra (como los trabajos de Óscar Saldarriaga Vélez, Renán Silva o Gonzalo Cataño), sino desde sus textos mismos (los trabajos del Grupo Fray Bartolomé de las Casas, dirigido por el profesor Leonardo Tovar González y la Biblioteca Virtual del Pensamiento Filosófico en Colombia fundada por el Profesor Manuel Domínguez Miranda). Para más información sobre el trabajo actual, véase el artículo de Leonardo Tovar González (2010) titulado "Colombia en la historiografía filosófica latinoamericana: rastros de una ausencia". 
dogmatismo extremo parecen ser las notas características de este singular personaje" (Valderrama Andrade, 1961, p. 113).

No obstante el relativo acuerdo que muestran el desinterés y los juicios sobre el trabajo de Rojas, este y otros dictámenes sobre su producción filosófica ${ }^{5}$ podrían considerarse, más que una característica propia de los textos que juzgan, el resultado de la perspectiva de análisis. No sería la primera vez que esto ocurra en Colombia. Otras investigaciones han mostrado que algunas de las claves de lectura de las fuentes locales tienden a generar incomprensión u olvido de aquello mismo que estudiamos: los conflictos de las élites regionales han ocultado y minusvalorado a través de la historiografía la acción durante la Independencia de los no-criollos $;$; la importación de modelos narrativos historiográficos desde Europa hacia Suramérica durante el siglo XIX habría impedido, a partir de entonces, y al menos hasta los años 80 del siglo XX, la comprensión de procesos locales a través de la imposición de unas "convenciones contra la cultura"; la producción intelectual colombiana ha sido cuando no ignorada, sí menospreciada o reducida a un mero efecto ideológico debido al énfasis que se hace en las luchas partidistas por

5 El siguiente diagnóstico fue tomado de una nota al pie del ya clásico trabajo sobre el Benthamismo en Colombia de Jaime Jaramillo Uribe titulado Bentham y los utilitaristas colombianos del siglo $X I X$ : "Rojas tuvo gran influencia política e intelectual a mediados del siglo XIX y fue considerado como su maestro por la generación radical que iniciaba su actuación en la vida pública hacia 1850 . Su actividad docente se ejerció por cerca de treinta años. Sus obras, casi todas resultado de su labor en las cátedras y en el periodismo, fueron publicadas por su discípulo Ángel María Galán en 1868. Del estudio de ellas se puede deducir fácilmente que no poseía una sólida preparación lingüística y es esa la razón de que su estilo sea incorrecto, confuso y difícil de leer. Tampoco poseía suficiente preparación filosófica, aunque entre sus contemporáneos tuvo fama de ser no solo un buen jurista sino también un filósofo. En la imagen que de él trazó Salvador Camacho Roldán en sus Memorias, se dice que «tenía poca imaginación, el análisis y la lógica eran sus armas y nunca se levantó a las regiones de la elocuencia»" (Jaramillo Uribe, 1962, pp. 18-19).

6 Dos libros ejemplares en esta dirección son Los indios de Pasto contra la República (1804-1824) de Jairo Gutiérrez Ramos, y para el caso de los negros y mulatos en la independencia de Cartagena, $E l$ fracaso de la nación de Alfonso Múnera.

7 Germán Colmenares (1997) afirma que el problema con las historias del siglo XIX suramericano no radica "en si nos referimos a la misma realidad, sino más bien en si hablamos el mismo lenguaje" (p. 101) y continúa más adelante, a propósito del valor que han tenido estas historias en la construcción de la nación, diciendo que "este fenómeno obliga reconocer el papel constructivo que jugó una imaginería historiográfica en la formación misma de la nación. Pero implica también que las imágenes no estaban destinadas a definir una realidad sino a prefigurarla. Muchas de las imágenes precedían de un fondo común de convenciones historiográficas europeas; en otras palabras, eran prestadas" (Colmenares, 1997, p. 102). 
el gobierno o a la ilusión de alcanzar una escasamente definida y, por lo general, multiforme modernidad. Sobre estas maneras de ver la escritura científica en ciencias sociales y filosofía en Colombia, se ha dicho que:

(...) el acercamiento a la producción escrita en el actual territorio colombiano no puede estar limitado al uso que recibió por parte de los administradores de lo público, ni al seguimiento o desviación de modelos regidos por una idea de la "modernidad" y las palabras asociadas a ella; tampoco puede reducirse a su utilidad inmediata en debates ideológicos o en la resolución de problemas públicos concretos. Estos factores son importantes, pero la historicidad de la escritura, esa actividad concreta que define a un grupo social específico, también debe ser pensada desde el ejercicio mismo de escribir. (López J., 2014, p. 63)

El énfasis en el ejercicio de escribir -en la observación tanto de los rasgos comunes de una práctica que se concreta en la impresión de textos y del reconocimiento público de estos dentro de los límites de una disciplina académica, como de los debates en torno a ellos-, exige analizar los escritos en su condición de productos intelectuales antes que buscar su lugar en los marcos interpretativos desde los que regularmente se interpretan ${ }^{8}$. Se espera un método así, que tenga

8 En otro lugar, esos rasgos comunes de la escritura se han llamado mínimo textual con el fin de establecer: "la serie de condiciones textuales - relativas a la práctica concreta de la escritura- que hacen de un documento un producto con el suficiente valor para ser objeto de publicación, discusión y tema de escritura entre quienes tenían por oficio ser escritor (quienes eran reconocidos por sus pares y publicaban documentos con algún impacto entre la comunidad de la cual hacían parte). Este mínimo textual no puede establecerse a priori, su historicidad, válgase esta verdad de Perogrullo, implica el que solo desde las fuentes mismas sea visible su talante” (López J., 2014, p. 68). Se trata de visibilizar la relevancia de lo escrito cuando nos enfrentamos a textos con pretensiones de cientificidad (uso de argumentos, capacidad predictiva, valor de verdad, etc.). Lo anterior porque el uso historiográfico común hasta la fecha tiende a olvidar "que los textos, además de condiciones del entorno fundamentales para su comprensión (situaciones específicas que los motivan, luchas de intereses, promoción y emulación de modelos foráneos), dependen también de procesos de elaboración textual que son determinantes (métodos de investigación locales o importados, inquietudes, respuestas, soluciones, temas de pasajeros o que constituyen una tradición). Por ello, para comprender esos textos que tanto se han usado y se usan en explicaciones historiográficas sobre el pasado colombiano, hace falta mostrar sus contenidos concretos. Es decir, se requiere dar cuenta del ejercicio efectivo de la escritura y, además, aclarar cómo pensar las relaciones de esos productos intelectuales (su condición lingüística) y su incuestionable conexión con los gobiernos de turno, asimismo establecer las diversas formas de interacción social de quienes escribían con sus pares nacionales y extranjeros, además, claro está, de otros sectores de la sociedad que los seguían en la plaza pública, los conocían a través de sus publicaciones, los respaldaban o rechazaban debido a las filiaciones partidistas o a juegos de intereses específicos (económicos, laborales, familiares)” (López J., 2014, pp. 62-63). 
efectos similares a los señalados por Bruno Latour respecto de las "contradicciones" que se podrían identificar en el "Informe sobre la fermentación denominada láctica” de Louis Pasteur. Según Latour, cuando dicho texto se valora con parejas conceptuales como realista/constructivista, empirista/racionalista el texto de Pasteur puede clasificarse, dependiendo del lugar del escrito en el que se haga el acento, en cada uno de los dos términos de las parejas conceptuales mencionadas. Aun así, en lugar de concluir que Pasteur se contradice, Latour (2001) afirma que:

(...) mientras no entendamos por qué lo que a nuestros ojos aparece como una contradicción no es en absoluto contradictorio para Pasteur seremos incapaces de aprender de aquellos seres u objetos que estudiamos, y nos limitaremos simplemente a imponer sobre su trabajo nuestras categorías filosóficas y nuestras metáforas conceptuales. (p. 160)

Insistir, pues, en los modelos conceptuales con que comprendemos la producción escrita (escuelas de pensamiento, periodizaciones de la historia de la filosofía o de la literatura europeas, dinámicas económicas como la inserción en el capitalismo internacional, proyecciones teleológicas como la esperanza de llegar a ser modernos, etc. (López J., 2014)), en este caso, usar modelos para comprender la producción filosófica de Ezequiel Rojas, posiblemente nos mantendría muy cerca de los juicios preexistentes, y probablemente, también, lejos de sus textos. En cambio, volver sobre tal producción escrita para entender sus propias dinámicas podría conducirnos a definir unos lugares de interpretación de la producción intelectual del actual territorio colombiano donde esta no se vea como atrasada, débil o irremediablemente atada a unos compromisos de clase.

Se trata de una propuesta de investigación para dar cuenta de las formas localizadas de producción de conocimiento. Esto es, de una forma de saber que aun pretendiendo ser universal, se encuentra en un marco espacio temporal y en relación con un ejercicio de escribir concreto que debe ser descrito. Un análisis de este tipo no puede partir, por ejemplo, de rasgos epistemológicos que se consideran condiciones universales de cualquier forma de saber, aunque, claro está, tendrá que negociarse con estas cuestiones por el camino, dado que los autores mismos se consideran en el marco de esta exigencia. Un análisis de las condiciones de la escritura tomará como punto de partida aspectos muy concretos de la escritura local que se examina: los textos que constituyen una discusión, la forma 
en que unos textos se alinean con una disciplinaria (filosofía, historia, etnología), o, como en este caso, el funcionamiento concreto de un concepto, el de ciencia.

Un análisis del ejercicio de escribir de los textos filosóficos de Ezequiel Rojas resulta particularmente relevante, no porque haya iniciado “(...) entre nosotros, la tarea de vincular las ideas políticas a concepciones más amplias del mundo, y ésta al interés, pasiones e impulsos sociales" (Jaramillo Uribe, 2001, p. 125), sino porque, como han señalado otros autores, él participó en varios de los debates más importantes de su tiempo y, además, su trabajo intelectual fue decisivo en una de las últimas transformaciones del saber en Colombia en la segunda mitad del siglo XIX . A ello se suma el papel que jugó como docente, jurista y filósofo para la generación de liberales radicales e incluso después, hasta su muerte a comienzos de la década de los años 70 .

Ahora bien, hacer un análisis del ejercicio de escribir en su obra a partir de funcionamiento del concepto de 'ciencia', se justifica porque además de la estabilidad de ese concepto a lo largo de toda su producción intelectual, este es central en muchas de las discusiones en las que se involucró: la noción de ciencia no solo permite identificar el tipo de objetos que interesaron a Rojas, sino la manera en que los aborda y, yendo más allá de una pura dimensión epistemológica, la utilidad que justifica el tipo de reflexión que lleva a cabo. A lo anterior, se suma la referencia constante y las múltiples funciones que Rojas le da a este concepto en sus distintos escritos. Así pues, la noción de ciencia es un punto de mira que permite, al mismo tiempo, una amplia perspectiva del conjunto de la obra de Rojas y el acceso detallado a aspectos muy concretos de su reflexión, tales como ciertos desarrollos argumentativos, procedimientos metodológicos y los objetivos del trabajo en conjunto.

Alcanzar claridad sobre el ejercicio de escribir que posibilita la producción filosófica de Rojas, abrirá camino para conectar dichos escritos con la producción foránea sin restarle importancia a la producción de conocimiento local; también

9 El profesor Oscar Saldarriaga Vélez (2009)-siguiendo las interpretaciones de Michel Foucault en torno a las condiciones enunciativas del decir de los encargados de la producción y administración del conocimiento-, avanza en la comprensión de la historia epistémica de los saberes del siglo XIX colombiano, y en esta línea ha mostrado que Rojas es el representante más destacado y uno de los últimos, no solo de una apuesta intelectual, sino de unas condiciones generales de la reflexión sobre el mundo que en Colombia llegaría a su fin a comienzos de la década del 70 del siglo XIX. 
dará una perspectiva de evaluación del lugar de esos textos en los debates de su tiempo, además del uso de los mismos en ámbitos como el gobierno y la militancia partidista. De igual modo, y particularmente en el presente artículo, volver sobre las condiciones de escritura de esos textos permitirá evaluar los diagnósticos que les han hecho hasta la fecha y las formas como se relacionan con claves interpretativas exógenas a la escritura misma. Claves como la explicación de la producción escrita local en función de los intereses de clase, partidistas u otros elementos sociales ${ }^{10}$; claves como la mirada evolutiva de los textos de Rojas que realizan Valderrama Andrade y Jaramillo Uribe (citados atrás); finalmente, claves como la historia de la filosofía según se usa en la siguiente cita:

En este apartado se intentará mostrar que las evidentes contradicciones e inconsistencias que se pueden detectar en el pensamiento de Ezequiel Rojas tienen que ver, al menos en parte, con la presencia en éste de dos vertientes de pensamiento opuestas: el positivismo filosófico entonces en boga, y la tradición metafísica imperante en la época colonial. (Quintana, 2006, p. 13)

Para dar cuenta del modo en que Ezequiel Rojas empleaba la noción de ciencia se tomarán como referencia los textos de este autor publicados en una compilación titulada Escritos morales ${ }^{11}$. No obstante, esta limitación en la bibliografía no será un problema para comprender la concepción general de ciencia que ope-

10 A propósito de lo que Rodríguez Valbuena considera el fracaso de los proyectos filosóficos liberales modernizadores del siglo XIX del actual territorio colombiano, este dice lo siguiente: "De manera que la debilidad de la filosofía moderna, expresada en la actitud claudicante del positivismo ante la neoescolástica, y el repliegue de la moral secular ante la mentalidad cuasifeudal, tiene sus raíces en fenómenos sociales más estructurales y se expresa no en la ausencia de la filosofía, sino en su exilio" (Valbuena, 2003, p. 11). También en relación con el pensamiento de Ezequiel Rojas, Rúsbel Martínez (2014) ha dicho que "Para el núcleo benthamista era importante dar forma a una legislación moderna que permitiera superar las fuentes iusnaturalistas del derecho predominantes en la legislación colonial que, por efecto de una ruptura incompleta con el pasado colonial español, pretendían instalarse en los fundamentos jurídicos de la legislación republicana a través de los planes de estudio de la carrera de derecho. El propósito no era desarrollar un cuerpo de legislación moderno, racional y científico, como señala Jaramillo (1964), sino dar forma a una legislación en la que los resortes ideológicos y políticos de las élites antibenthamistas quedaran neutralizados, en particular la presencia de la moral católica en la legislación y el influjo social del clero a través del ministerio público de la predicación" (pp. 761-762).

11 Germán Marquínez Argote, compilador de la obra, la introduce así en la presentación: "La presente edición de Escritos éticos es una reproducción facsimilar del segundo volumen de Obras del doctor Ezequiel Rojas, recogidas por su discípulo Ángel María Galán (1836-1904) y editadas en Bogotá, Imprenta Especial, 1882". 
ra en sus escritos ${ }^{12}$. Como se verá en el siguiente apartado, la selección además de alusiones directas a otras ciencias como la astronomía, la física, la gramática y la lógica, muestra que el carácter de ciencia es común a todos los saberes, en otras palabras, que no habría diferencia, según los criterios del mismo Rojas, respecto a la naturaleza del objeto, método de análisis y finalidad entre las ciencias naturales y las ciencias morales y políticas (como él decía).

Estos tres elementos -objeto, método y finalidad-, rasgos en los que Ezequiel Rojas insiste cuando compara las diferentes ciencias, permitirán establecer puntos de mira bien definidos en sus textos y, se espera, dejen abierto un programa de investigación en torno a la obra de Rojas en su conjunto.

En concordancia con ello, al dar cuenta del objeto se muestra lo que Ezequiel Rojas consideró el origen del conocimiento, su carácter universal y la forma como se evalúa la verdad de un juicio y, por esta vía, se muestra la consistencia de algunos de los rasgos más criticados de su estilo argumentativo. El método, por su parte, define el camino que sigue la ciencia en su construcción de conocimientos y la relación entre los hechos del mundo con el lenguaje, de aquí se desprende la imagen particular del lenguaje y la relación de este con la verdad que caracterizó a la obra de Rojas. Por último, la finalidad establece el lugar que Rojas dio a la ciencia en la sociedad, su destino entre los hombres y su relación con el progreso de los grupos humanos a través de su concepción de la ciencia como medio y fin del mundo social, aspecto crucial que evidencia cómo una reflexión sobre las bases, rasgos y funciones de la ciencia, implica desdibujar los límites que hacen diferentes entre sí a las inquietudes epistemológicas, ontológicas, éticas y políticas. En conjunto, esta mirada de la obra de Rojas disuelve algunas acusaciones respecto a las contradicciones internas de su trabajo y muestra que al menos una parte del tipo específico de trabajo filosófico en el actual territorio colombiano ${ }^{13}$,

12 Muchas más ayudarían introduciendo matices, puliendo formulaciones o ampliando las consecuencias de la noción de ciencia que defiende Rojas. Pero para los objetivos de este escrito es suficiente este conjunto de textos filosóficos, por su cantidad y distancia en el tiempo de publicación (entre 1836 y 1872 , además de un texto póstumo publicado 1873 y dos inéditos).

13 Después de 1831 - con la disolución de lo comúnmente se llama la "Gran Colombia"- el actual territorio Colombiano se llamó hasta 1861 Nueva Granada; luego, bajo el proyecto federalista y hasta 1863: Confederación granadina y, después, Estados unidos de Colombia, nombre que cambiará, finalmente, en 1886 con el nuevo régimen centralista a República de Colombia. 
además de una consistencia interna suficiente, tuvo un modo de ser que, al menos analíticamente, puede distinguirse y aislarse.

\section{Objeto: los seres, sus propiedades y sus causas}

Para Rojas, las ciencias, no importa si son naturales o morales y políticas, tratan de hechos (cosas o actos) y de sus propiedades. "Se da el nombre de hecho a todo lo que existe o sucede (...) son las cosas, las personas, las acciones ejecutadas por estas, y las respectivas propiedades que les son inherentes" (Rojas, 1988, p. 142).

Cada ciencia tiene por objeto un orden de hechos que le es peculiar. La descripción de las propiedades y naturaleza del alma corresponde a la psicología; así como la descripción de las leyes naturales en virtud de las cuales las sociedades existen, se desarrollan, progresan o se arruinan, es el objeto de las ciencias políticas y de la moral universal. (Rojas, 1988, p. 118) ${ }^{14}$

A propósito de estas últimas, las ciencias morales y políticas, Rojas muestra un elemento adicional a los hechos que hace parte del objeto de las ciencias en general: sus causas.

Descubrir en las leyes de la naturaleza la verdadera cualidad que caracteriza los actos humanos de malos, mejor dicho, descubrir las causas o motivos que hubo y hay para prohibirlos, es descubrir la razón científica de su modo de ser; es descubrir las causas secundarias creadas por Dios, y de donde han recibido su modo de ser.

Estudiar los hechos con esta mira, es estudiarlos filosófica y científicamente: bajo este aspecto ofrecí considerarlos para demostrar que el bien y el mal, lo bueno y lo malo, lo moral y lo inmoral, el mérito y el demérito, los derechos y las obligaciones, nacen de propiedades inherentes en los hombres, en sus actos y en las cosas, es decir, de leyes de su naturaleza, y que, por consiguiente, su exposición es lo que, hablando con propiedad, puede llamarse ciencia de la moral. (Rojas, 1988, pp. 173-174).

14 Aunque la edición citada toma la ortografía usada por Ángel María Galán, la ortografía de los textos de Rojas está actualizada según los usos de nuestro tiempo. 
Para el autor, estos objetos son por disposición divina algo en sí mismos, su existencia no está mediada por una naturaleza humana (la operatividad de la razón, la historicidad del saber), sino que ellos son preexistentes al conocimiento de los mismos. Y si el individuo al hacer ciencia cumple alguna función, además de percibir los hechos, no es la de dar universalidad al conocimiento a través de la razón, sino la de usar las facultades que posee conforme a la disposición natural de las mismas en la identificación de sus causas (las leyes que los hechos):

Para la resolución de las cuestiones científicas, la autoridad que Dios estableció fue la inteligencia de que dotó al hombre, es decir, las facultades con que adornó su alma, y los sentidos que le dio por instrumentos, para que con estos medios estudiase la naturaleza y conociese las leyes a que sometió el orden físico y moral. -Para la resolución de estas cuestiones Dios no dio infalibilidad a ningún hombre ni a ninguna autoridad. Los hechos bien probados y las demostraciones lógicas y concluyentes, son los únicos infalibles en estas materias, y los únicos jueces que admito. (Rojas, 1988, pp. 71-72)

Conocer los hechos consistirá en identificarlos y poder dar cuenta de las propiedades y leyes que los rigen a través del uso correcto del lenguaje orientado por la lógica. Este modo de ser del conocimiento depende de una disposición divina, del orden específico del que Dios dotó a la naturaleza (sus leyes, las cuales son análogas a las del resto de hechos). Conocer los hechos es conocer esta disposición, hacer ciencia, es decir, establecer un discurso universal sobre el mundo ${ }^{15}$, es poder explicarla y describirla a través del lenguaje.

15 La universalidad es uno de los objetivos de la reflexión de Rojas, el mundo terminado del que habla es la garantía de esa universalidad, pues lo conocemos como es y ese ser no varía, solo la perfección de nuestro conocimiento: "Dejo probado que la maldad de las acciones la constituye la propiedad que tienen de hacer desgraciados a los hombres, y su bondad, la que tienen de hacer su felicidad; que estas propiedades son inherentes a su naturaleza; que no son obra de los legisladores humanos ni de ninguna religión positiva, y que su conocimiento y descripción constituyen la ciencia de la moral: esta es y tiene que ser, como todas las otras, la descripción de leyes de la naturaleza: no puede ser otra cosa. Tiene, pues, los mismos caracteres que ellas: es, pues, inmutable y universal, como son inmutables y universales la geometría, la química, etc." (Rojas, 1988, pp. 121-122).

Tomar en cuenta esta ontología de seres creados y fijos como el fundamento de la reflexión de Rojas desmiente la siguiente afirmación de Jaramillo Uribe, la cual ve en esta obra una falsa identidad entre universalismo e innatismo: "lo que Rojas quería afirmar era el origen sensorial y empírico del conocimiento y la consiguiente negación de toda idea universal, o como él decía, innata" (Jaramillo Uribe, 2001, p. 127). 
Las palabras, lo repito, son signos de las ideas: para percibir éstas con claridad es indispensable conocer la naturaleza de aquéllos. -Esta nace de la naturaleza del pensamiento, o sea de las ideas mismas: me explicaré con un ejemplo. Veo un caballo, y veo que es rucio. He tenido tres percepciones: la del caballo, la del color y la de existir éste en aquél: he formado dos ideas y un juicio: la primera la de un ser, el caballo; la segunda la de una cualidad, el color, y el tercero la percepción de estar una idea contenida en la otra, más claro, la de que el caballo tiene tal cualidad, o como dicen los hombres de la ciencia, la de estar el atributo contenido en el sujeto.

Como se ve, en el pensamiento hay dos ideas de distinta naturaleza: la del ser y la de la cualidad. -La primera existe por sí misma, y es independiente: la segunda no es independiente ni existe por sí misma.

Las dos ideas son de distinta clase: han necesitado, pues, signos de distinta naturaleza: a los primeros se les llama sustantivos y a los segundos adjetivos.

He necesitado recordar al lector estas ideas para poder deducir lógicamente estas consecuencias: luego los adjetivos expresan ideas de propiedades o circunstancias que existen en los seres, y que no existen por sí mismas; luego los adjetivos bueno y malo son signos que representan cualidades de los seres, y que no existen sin sujeto en quien residir; luego el adjetivo bueno no representa la idea de una entidad real existente por sí misma, sino la de una propiedad existente en un sujeto. (Rojas, 1988, p. 97)

La ciencia es, entonces, un compendio de los hechos del mundo que podemos recoger a través de las sensaciones, esos hechos se asocian por leyes que dan cuenta de su vínculo causal. El modo en que se concretan esos hechos y leyes en conocimiento es el lenguaje, el cual no es otra cosa que la representación de las ideas que nos hacemos del mundo a través de palabras (que tienen una función gramatical en relación con el objeto que representan). Estas condiciones generales le permiten a Rojas transitar sin inconvenientes entre las cuestiones de las ciencias naturales y las de las ciencias morales y políticas, ya que su dependencia del mundo las hace idénticas.

No estando impresas en el espíritu del hombre las leyes naturales que establecen el orden, de dónde depende el bien y el mal, lo bueno y lo malo, ¿cuál es el medio por el cual puede descubrirlas y conocerlas para obrar de acuerdo 
con ellas? ¿El medio que el hombre tiene para descubrir y conocer estas leyes, es diverso del que tiene para descubrir y conocer las del orden físico ${ }^{16}$

Esta cuestión tiene su resolución en la siguiente: -¿Por qué medios adquiere y forma el hombre sus ideas y sus juicios? En otros términos: no habiendo ideas innatas, siendo todas adquiridas, ¿cuáles son los medios con que Dios dotó al hombre para que adquiera ideas; forme juicios y conozca el orden físico y el moral?

Hacer consistir la felicidad en el orden, es hacerla consistir en la observación de las leyes naturales. Estas son las propiedades constitutivas de los seres, y por consiguiente las constitutivas del hombre; luego es en él en donde pueden descubrirse y aprenderse las leyes naturales a que debe someterse y arreglar su conducta. (Rojas, 1988, p. 92)

Conviene, antes de continuar, llamar la atención sobre dos aspectos típicos de estos escritos que se evidencian en los tres párrafos anteriores. El primer aspecto consiste en que Rojas, para contestar una pregunta, propone contestar otra que sería una especie de reformulación de la primera; lo que suele ser, como en este caso, el paso de un aspecto de la misma cuestión implicado en la primera (en los párrafos citados, por ejemplo: de lo que podemos adquirir a las condiciones de adquisición que nos son propias), o como en otros, un cambio de nivel de análisis (de las ciencias naturales a las morales y políticas, de lo físico a lo moral, o de lo individual a lo social). El segundo aspecto tiene que ver con el modo como trata al hombre, no le otorga ningún privilegio con respecto de los demás objetos del mundo y de ese modo, el mundo, se revela como una superficie única y homogénea: la naturaleza. Así, sobre esa superficie homogénea, las reformulaciones y los desplazamientos, que a veces parecen incoherencias, resultan legítimos.

\section{Método: el lenguaje y el error}

El peso ontológico due Rojas le otorga al orden natural en sus reflexiones epistemológicas permite comprender procedimientos escriturales como los desplazamientos en el punto de interés. Esto con el fin de responder a sus pregun-

16 La cuestión del innatismo es una discusión con Manuel María Madiedo (1815-1888) que se desarrolla en una serie de parágrafos (a partir del XIX) del libro de Rojas titulado Filosofía Moral. 
tas o a la formulación de identidades entre, por ejemplo, las ciencias naturales y las ciencias morales y políticas (que tratan con materiales similares, se fundan sobre los mismos procedimientos y tienen la misma finalidad). Enfatizar en la escritura, antes que en la historia intelectual o en la historia de la filosofía, es un procedimiento que muestra que al menos en el marco de su reflexión, estos desplazamientos y estas identificaciones no son necesariamente contradictorios o inconsistentes.

Más bien, la naturalidad con que trata los cambios de nivel y las identidades que encuentra entre cuestiones que hoy podrían parecernos de naturaleza diversa, le permite avanzar en sus trabajos con preguntas concretas relacionadas con el escaso progreso de las ciencias morales y políticas dada sus similitudes con otras ciencias más firmes o el origen del error cuando la evidencia del orden natural es tan contundente como él lo afirma.

Los hechos que son objeto de las ciencias morales y políticas no se hallan en el mismo caso: los que los estudian, o como moralistas o como publicistas, no los tienen a su disposición para observarlos y repetir las experiencias. Hay acciones e instituciones cuyos efectos no pueden ser conocidos sino en el trascurso de mucho tiempo y por hombres muy observadores.

Hay dos causas más que impiden y han impedido el conocimiento de aquellos hechos, es decir, la formación y propagación de dichas ciencias: 1.a intereses particulares, y 2.a los métodos empleados para su estudio. (Rojas, 1988, p. 114)

La combinación de los tres obstáculos explica la situación de atraso de las ciencias morales y políticas respecto, por ejemplo, a la física. No obstante, Rojas no le presta mayor interés al primero de ellos (exclusivo de las ciencias morales); posiblemente, el que se trate de una cuestión de tiempo de observación lo deja sin mucho que decir al respecto. Los otros dos obstáculos son, en cambio, de más profundidad y por ello les dedica un espacio importante en su reflexión. La forma de enfrentar el segundo, el de los intereses particulares, quedará clara más adelante, por lo pronto detengámonos en el tercero. "El método experimental es un exorcista poderoso: él ha lanzado el sofisma de autoridad, y todos los demás, del mundo material: en consecuencia se han podido formar las ciencias que se ocupan de los hechos del orden físico, y éstas han podido llegar al grado de perfección en que hoy se hallan" (Rojas, 1988, p. 346), como ya se sabe, este método es aplicable también a las ciencias políticas y morales. 
La igualdad de su naturaleza en tanto que ciencias, la igualdad de sus objetos en tanto que seres con propiedades, nos obliga a buscar cuáles son esos hechos relativos a la acción humana que podrían darse a dicho método. Tales hechos, objeto de las ciencias morales y políticas, no pueden ser los deberes o las buenas intenciones, ya que ambas cosas son empíricamente imperceptibles y, aunque la opinión de quién realiza las acciones (sea en relación con un deber o motivado por una intención concreta) es la única fuente desde la que se puede afirmar con certeza los motivos de los actos, ella no es una fuente de fiar -no se puede ser juez y parte-.

El aprieto en el que se encuentra cualquier demostración empírica de los principios de la acción humana explica los vínculos de Rojas con Bentham, mejor, permite mostrar la necesidad argumentativa que el utilitarismo benthamista cubre en la reflexión de Rojas ${ }^{17}$. Ya desde su primera publicación titulada Jeremías Bentham ${ }^{18}$, Rojas establece un compromiso con la obra de este autor inglés que mantendrá firme hasta su muerte, ello con el fin de fundamentar su método de investigación, en lo que Rojas considera un hecho incontrovertible:

El hombre, cualquiera que sea el idioma que hable, el clima que habite o la religión que profese, halla en el fondo de su corazón un impulso irresistible hacia su felicidad: que no se llama ni se considera feliz cuando sufre, es decir, cuando sus sensaciones son desagradables, ora sean físicos, ora sean morales estos sufrimientos, y sean cuales fueren las causas que los producen: que cree sí haber logrado la felicidad posible en este valle de miserias cuando no sufre, esto es, cuando sus sensaciones son agradables, lo que solo sucede cuando ni

17 En lugar de cubrir podría decirse que es la mirada utilitarista la que genera estas inquietudes en los escritos de Rojas, sin embargo, no parece posible ofrecer pruebas para decantarse por una u otra opción. Más allá de esa etérea posibilidad, en tanto aquí se habla de ejercicio de escribir, la cuestión, casi irrelevante de si Bentham es el efecto o la causa, se clausura tomando la primera opción. Ello debido a que este orden expositivo hace innecesario, ante el hecho cumplido, ocuparse de la causa del mismo, o de comparar la lectura de Bentham que hace Rojas con otra hegemónica o más popular o correcta. La justificación de este modo de proceder está en la elección metodológica misma: lo que pesa más en el análisis sigue siendo el texto de Rojas, los problemas que se plantea, las discusiones que enfrenta y no alguna versión de historia oficial de la filosofía, de los intelectuales, de los intereses de clase.

18 En el primer apartado del texto afirma, a propósito de la disputa en la que se está involucrando, que se trata de una lucha desigual, pues quien enfrenta con ese escrito a un maestro, es apenas un "hombre que por primera vez somete al público sus escritos" (Rojas 1988, p. 6). 
males físicos ni morales lo afectan: que este es el estado que anhelamos, y este el fin que nos proponemos en todas nuestras operaciones. (Rojas, 1988, p. 6)

Esta ambición de la felicidad se corresponde, no solo con los hechos percibidos directamente por él, sino con la historia de la humanidad misma. Así, Rojas en este mismo texto reconstruye dicha historia y muestra cómo a lo largo de ella las reglas que ayudan a preservarla han tenido, siendo las mismas, diversos nombres (conciencia, derecho natural, sentido íntimo, razón eterna). En nuestro tiempo:

(...) [S] ha presentado Bentham reproduciendo con todas las explicaciones correspondientes, un principio que es tan viejo como el mundo, reducido a decir: "que no se puede conocer la bondad y maldad de las acciones y de las leyes, sino por su influencia sobre la felicidad de los hombres, es decir, por su tendencia a producir bienes o males, esto es, placeres o penas. Que, por consiguiente, para saber lo que es moral o legislativamente bueno, es preciso abrir a cada acción o cada ley dos cuentas, inscribiendo en la una todos los males de cualquiera clase o naturaleza que fuesen, y cualquiera que fuese el que los sufría, haciendo lo mismo en la cuenta de los bienes, y que después de este cálculo moral, se comparasen los bienes y los males por medio de una resta, concluyendo que la acción es buena si produce más bienes que males, y mala en el caso contrario". Este es el principio atacado por inmoral, que se tiene por peligroso, que tanto ha escandalizado, y que Bentham llama de la utilidad. (Rojas, 1988, p. 8).

Para decirlo brevemente, la definición utilitarista de la felicidad (más placer y menos dolor), le proporcionó a Rojas un terreno empírico sobre el cual echar las raíces de las ciencias morales y políticas. Sin embargo, la firmeza que encontró en las sensaciones no era compartida por todos sus contemporáneos (quienes, como lo muestra la cita, lo consideraban inmoral y peligroso). Para muchos, se trataba de un material inmundo sobre el que nada digno podía edificarse, mucho menos la moral o el Estado. Dado que Rojas asume la corrección de las tesis de Bentham como un resultado del trabajo empírico, para él sus opositores simplemente ignoran los resultados incontrastables del método experimental. Error imperdonable pues ellos no habrían tomado en cuenta que, siendo la naturaleza algo terminado, carece de sentido calificarla de despreciable, no se puede valorar como error lo que de suyo es. 
Los que forman las ciencias lo primero de que tienen que ocuparse es, de descubrir y conocer los fundamentos que ellas tienen: ellos no los inventan, ni pueden ponerles a su antojo los que mejor les parezca: ellos no edifican ni elijen materiales: el templo lo encuentran construido, con las bases y materiales con que el arquitecto tuvo a bien formarlo (...)

No se trata, pues, de saber si el placer y el dolor son o no materiales inmundos, indignos de que se les considere como bien o como mal, ni si sería mejor que el hombre fuese feliz cuando sufre y desgraciado cuando goza. -Estas cuestiones debemos reservarlas para que las resuelvan los filósofos y moralistas que se ocupan en redactar las reformas que, en su modesta opinión, Dios debe hacer al mundo. (Rojas, 1988, pp. 93-94)

El cierre irónico de esta cita y su referencia a la "redacción” no es en vano. En varios lugares insiste en que la ciencia no es un romance (refiriéndose con esto a la composición poética en versos octosílabos), es decir, que ella no se ocupa, ni se construye solo de y con palabras (Rojas, 1988, p. 76). Únicamente los hechos hacen la ciencia y el lenguaje no está para indicarnos cómo deben ser las cosas, sino que en su calidad de signos referidos al mundo empírico, debe dar cuenta de lo que percibimos a través del método experimental.

El problema que emerge de esta comprensión del lenguaje en su relación con el mundo es que mientras el primero permanece invariable, el segundo sufre una continua renovación. De todas formas, Rojas no entenderá este cambio permanente del lenguaje, como un movimiento autónomo (a través del cambio concreto de las lenguas) al estilo de los pensadores de la ciencia del lenguaje al estilo de un Miguel Antonio Caro (López J., 2008, pp. 73-101), sino que lo justifica como una evolución resultado del mejor conocimiento del mundo:

Los progresos de las ciencias llevan siempre consigo el perfeccionamiento de los signos con que se las expone: cuanto mejor se conocen todas las propiedades de los hechos que constituyen el objeto de una ciencia, más se distinguen los unos de los otros, más se les puede ordenar, dividir y subdividir, en una palabra, más se les puede clasificar, según sus condiciones y cualidades. ¿Existen los hechos? ¿Estos tienen cualidades que los diferencian los unos de los otros? Debe, pues, haber signos distintos que los representen. Hacer uso de una misma palabra para representar ideas diferentes, es la causa principal de la confusión de las ideas; de los errores en los juicios; de la vaguedad en los 
discursos; de la divergencia en las opiniones, y de que los hombres no puedan ponerse de acuerdo.

A las ciencias no se las altera ni se las cambia porque se precisen con claridad las ideas expresadas con los signos que forman su nomenclatura. (Rojas, 1988, p. 128)

Atenerse a la nomenclatura es hablar con verdad, y justo en ello radica la cuestión moral tras el error. Como se mostró atrás, el error, desde el punto de vista epistemológico de Rojas, no está ni en el mundo, ni en nuestra manera de percibirlo - de lo contrario la garantía del conocimiento estaría perdida-. Así, más allá un problema de percepción, el error está en el modo en que damos cuenta de ese mundo, en el uso de las palabras y nuestras formas de argumentar. Sobre las primeras dice Rojas (1988):

Los gobiernos y los legisladores, para fascinar, y para que no se descubra la naturaleza de sus actos, han ocurrido al medio de enmascararlos bautizándolos con nombres impostores. A su conducta la llaman politica: ellos no dicen la moral del gobierno es esta: ellos dicen, la politica del gobierno es esta. Si hablasen de moral, todos conocerían cuándo obran moralmente y cuándo no; pero hablando de política, no es fácil formar este juicio: la palabra politica no representa ideas claras y precisas: fácil es, pues, engañar con ella.

La moral prohíbe a todos los hombres, y a todas las entidades que de ellos se forman, el apoderarse de los bienes ajenos contra la voluntad de sus dueños, por la fuerza, con astucia o con engaño. Regístrese la historia de los gobiernos y legisladores de todas clases, y se hallará la voluntaria y maliciosa violación de este precepto, enmascarada con términos impostores. Hacen bancarrota fraudulenta, y a este acto lo llaman organizar el crédito nacional: despojan de sus bienes a sus dueños, y a este acto lo llaman expropiar o desamortizar: se obliga al acreedor a cancelar ciento recibiendo diez, y a esto se llama aprovechamiento: arrancan de la tercera parte de la población los fondos para los gastos de toda ella, y lo llaman contribución: arrancan contribuciones de esta clase, conminando con penas eternas a los que no las pagan, y a esto llaman limosna, etc. La ciencia de algunos publicistas, ministros y legisladores consiste en inventar medios, argucias y supercherías para despojar de sus bienes a los particulares, para alzarse con sus créditos, para cancelar las deudas sin pagarlas (conminando con que no se pagará el crédito si no se dan ciento por diez), 
para echar, por el medio que se puede, el agua a su molino, o al del amigo, etc. (pp. 244-245)

La primera forma del error radica en los significados de las palabras que no se corresponden con el estado de cosas del mundo que percibimos o en las falsas creencias que promueven un uso equivocado de estas. Un buen ejemplo de este tipo de error es el uso ambiguo de la palabra "moral" debido a su doble carácter de sustantivo y adjetivo ${ }^{19}$.

El segundo lugar del error está en la argumentación; por ello Rojas emplea largos pasajes en demostrar la falsedad de la autoridad como razón a favor de una o mostrando cómo muchas de las afirmaciones en contra de Bentham se fundan no en buenas razones, sino en peticiones de principio. Ejemplos de este último caso son las refutaciones de los distintos intentos por probar que la moral se funda en ideas innatas, o en el sentido común, o en las morales particulares de las diversas religiones (Rojas, 1988, pp. 279-286).

El papel que Rojas da a la argumentación explica que en sus reflexiones epistemológicas, además de asuntos ontológicos (debido a la necesidad de establecer el modo de ser del mundo para justificar el método, la universalidad de los resultados y la relativa identidad de las ciencias), se traten con regularidad cuestiones como el modo correcto e incorrecto de dar razones, la ilegalidad de los sofismas o el uso adecuado de la lógica. Estas disertaciones sobre el lenguaje son, en términos suyos, cuestiones de argumentación - aunque no confronte a la lógica formal, ni pretenda cubrir un espacio descuidado por ella como podríamos esperar hoy día-.

Rojas trata como iguales a la argumentación y a la lógica formal, bastantes pasajes y referencias indirectas muestran lo difícil que sería identificar a lo largo

19 "El conjunto de preceptos que prohíben aquellos actos, que en todo tiempo y lugar tienen la propiedad de obrar sobre las sociedades haciéndolas desgraciadas, reunido a los que mandan o permiten aquellos que en todo tiempo y lugar obran sobre ellas haciéndolas felices, es lo que constituye la moral universal".

"El conjunto de preceptos, que prohíben, mandan o permiten los actos humanos, contenidos en los evangelios, constituye la moral cristiana. El conjunto de preceptos contenidos en el Alcorán [sic] constituye la moral mahometana, etc.".

"Tomada la palabra moral sustantivamente, es que se dice que hay muchas morales, es decir, muchos Códigos de moral; que hay moral buena y moral mala; que hay tantas morales como religiones; que estando éstas divididas en sectas, hay tantas morales como sectas, y que, aun cuando en ellas haya preceptos que les sean comunes, hay muchos que son opuestos y otros que son diversos" (Rojas, 1988, pp. 273-274). 
de su obra una distinción entre ambas. La argumentación trataría, entonces, del buen razonamiento tanto como de la definición y presentación de los problemas que traen algunos sofismas (en sus textos, además del principio de autoridad, revisa los sofismas de "personalidades injuriosas" ${ }^{20}$ - ad hominem, como corrientemente la llamamos en la actualidad- y el de "Falsedad"21 o "falsa doctrina").

La naturaleza de tales sofismas no se mueve en el nivel operativo de los errores en los procedimientos argumentativos (validez), sino en el nivel epistemológico del acceso a la verdad. Para Rojas, usar sofismas es decir mentiras, equivocarse -intencionalmente o no- respecto a la verdad de los hechos.

Finalidad: La ciencia como medio y fin

No obstante el marcado interés epistemológico, la reflexión de Rojas por el lenguaje y la ciencia desborda con mucho los límites de una pregunta por el conocimiento o el uso correcto de la lógica. Dos razones más, íntimamente vinculadas entre sí, presentes en una serie de respuestas dadas a un articulista anónimo que pretendía refutar el utilitarismo (artículo y cartas publicadas en prensa nacional) dan cuenta de ello. Una se relaciona con la moral, la otra con la políti$\mathrm{ca}^{22}$. La primera muestra cómo las armas que usa el señor N.N., así firma el articulista, son errores lógicos (desde el punto de vista de Rojas, no dan cuenta de la verdad) que además de apartarlo de la moral, lo apartan del catolicismo (aunque NN se considere a sí mismo católico).

20 "Personalidades injuriosas. Cuando se trata de saber si una tesis es verdadera o falsa, emplear calificativos injuriosos o calumniosos, es un falaz modo de razonar, es un sofisma” (Rojas, 1988, p. 348).

21 "Falsedad. Cuando hay necesidad de sostener que una doctrina es falsa, y no se tienen razones para ello, entre otros medios oratorios se hace uso del de alterar la verdad, es decir, de falsificar la doctrina: estas falsificaciones se hacen, o exagerando, u omitiendo, o sustituyendo: por estos medios se forma un endriago al amaño del que combate, y al que se lo puede pulverizar fácilmente" (Rojas, 1988, p. 349).

22 Aquí podría explorarse, además, una cuestión psicológica que parece atizar muchos de los debates de este periodo: el honor. En "A la cuestión" dice: "aunque lego en teología le aceptaba el reto en este terreno, por honor y porque no me volviese a tratar de cobarde" (Rojas, 1988, p. 356), y en otro lugar afirma: "Trátase de saber si la ciencia que enseña Bentham es verdadera o falsa: el señor N. N. para dar la persuasión de que es falsa, afirma audaz y desvergonzadamente, que los utilitaristas son ateos, corrompidos, perversos, miserables, cobardes, traidores, etc." (Rojas, 1988, p. 348). 
1. ${ }^{\circ}$ que suponiendo que los utilitaristas somos todo lo que dice el señor $\mathrm{N}$. $\mathrm{N}$. de aquí no se deduce que dicha ciencia sea falsa; $2 .^{\circ}$ que siendo inconducentes en la cuestión las imputaciones que nos hace el señor N. N. no le ha sido lícito ni permitido hacerlas; $3 .^{\circ}$ que siendo falsos e infamantes los hechos que nos atribuye el señor N. N. las imputaciones son calumniosas: $4^{\circ}{ }^{\circ}$ que aquellas imputaciones solo prueban que quien las hace es procaz y calumniante. (Rojas, 1988, p. 348)

Además de las calumnias, soportadas en sofismas contra Rojas, el señor N.N. ha señalado de falsas las investigaciones de J. Bentham, es decir, ha negado los resultados irrefutables del método científico, procedimientos ambos (formular calumnias y rechazar evidencias), moralmente reprobables ${ }^{23}$. Como si fuera poco, siguiendo a Rojas, el señor N.N. no opone a sus tesis hechos ni buenas razones, solo afirmaciones fundadas en el principio de autoridad. Con ello, al error lógico y al acto inmoral se les añade, en tanto atañe a la vida feliz (objetivo último de los hombres) de los miembros de una nación y al desarrollo de la misma, un indeseable efecto político: el retraso social que produce el mencionado principio. El cual, por su propia naturaleza, tiende a dejar las cosas como están y a perpetuar la situación de oscuridad en que viven los hombres, dado que no se cuestiona ni lo que han dicho y dicen los doctos, ni lo que "han practicado todas las generaciones" (Rojas, 1988, p. 342), pero, sobre todo, no cuestiona la verdad en su relación con el destino de las naciones. La forma política del error se clarifica en la siguiente cita:

El conocimiento de las ciencias y la fiel ejecución del arte, es decir, de los preceptos o reglas que de ellas se deduzcan, son las causas de la dicha y prosperidad de las naciones. El conocimiento y práctica de los falsos sistemas es la causa del malestar, de la miseria y ruina de las sociedades. Esto quiere decir que la verdad es la causa de la felicidad de las naciones, y que el error es la causa de su desgracia.

El uso de la verdadera lógica, conduce al conocimiento de la verdad. El uso de los sofismas, es decir, el uso de los falsos modos de raciocinar, o sea, de la falsa lógica, conduce al error. Esto también quiere decir, que el conocimiento y uso de la verdadera lógica, es lo que conduce a los hombres a su dicha y

23 "Hacer uso de sofismas, especialmente en negocios graves, es, pues, un acto malo, frecuentemente inmoral y por consiguiente funestísimo para las sociedades y sus miembros” (Rojas, 1988, p. 337). 
perfeccionamiento, y que el conocimiento y uso de los sofismas es lo que los conduce a la desgracia y a la ruina. (Rojas, 1988, p. 337)

¿A qué se debe esta creencia? ¿Por qué en la obra de Rojas, en la cual se insiste en el correcto uso de las razones y la lógica, es tan difícil encontrar una argumentación satisfactoria a favor del vínculo entre el conocimiento de la verdad, la conducta correcta y el progreso de las naciones? ¿Habrá alguna explicación que se encuentre en sus trabajos escritos y que no suscite un desprecio intelectual de su obra o una reducción contextualista a intereses de clase ocultos por una falsa conciencia o por una ciencia ideologizada? Toda la obra filosófica de Rojas es un buen lugar para dar cuenta de las relaciones entre conocimiento y acción, tal vez uno de los problemas filosóficos de mayor profundidad en su trabajo. Por lo pronto, recogiendo lo que se ha dicho, se puede adelantar una posible explicación de la ausencia de razones que justifiquen el tránsito entre la epistemología, la moral y la política.

Aunque Rojas distingue entre lo moral y lo epistemológico, ambos aspectos de la vida humana, como el resto de las cosas del mundo, están asociados necesariamente con la causalidad; todo opera, según él mismo lo afirma, a partir de este registro. Por ello no es extraño que diga que "el hombre es efecto de las causas que contribuyen a su formación en lo físico, en lo intelectual y en lo moral" (Rojas, 1988, p. 340). La fusión de esos tres ámbitos en los márgenes de la causalidad le permite al autor pasar de las ciencias empíricas a las morales sin ninguna dificultad. Basta fijarse, a propósito de las utilidades que arrojó el método experimental a las ciencias físicas, en lo que él mismo dice:

Cuando aquel método acabe de lanzar los sofismas del mundo moral, entonces las ciencias que se ocupan de los hechos de este orden, se perfeccionarán, se extenderán y producirán para las sociedades los frutos que hoy recogen del progreso de las ciencias físicas, de las naturales y de las exactas. (Rojas, 1988 p. 346)

Se trata de una apuesta por la comprensión del mundo que solo es posible por su condición causal. Para Rojas no hay mucho más que explicar, por eso son prácticamente inexistentes sus argumentos respecto al papel activo que desempeña la lógica en el conocimiento. En otras palabras, la certeza de que los hechos 
naturales y humanos tienen propiedades que les son exclusivas (físicas ${ }^{24}$ y mora$\operatorname{les}^{25}$ ) y de que el conocimiento consiste solamente en dar cuenta de ellas a través de un uso honesto del lenguaje, le da a Rojas una imagen de la lógica como algo que si se usa bien, muestra las propiedades y causas de los hechos del mundo, pero que si se usa mal, interviene la verdad misma con adornos retóricos y sofismas. Por ello, tampoco puede pensar el sofisma como un error de procedimiento, sino como un acto que atenta contra la verdad y que puede llegar a ser inmoral; se ve con claridad cómo se integran, ya no epistemología y ontología, sino lógica y moral.

Esta segunda unión tiene que ver con el papel activo del error lógico y el uso malintencionado de este. La buena lógica no sería otra cosa que ajustarse a lo que ocurre en el mundo, las buenas razones, que sirven como fundamento de lo dicho, se apoyarían a su vez en la percepción de los hechos tal como son y sin modificarlos ${ }^{26}$.

Las ciencias morales y políticas, para alcanzar las glorias de las ciencias naturales, tendrán que observar sus propios hechos particulares: los actos humanos. Ellas tendrán que explicar sus causas y desde allí valorar la conducta de los hombres en tanto que seres individuales con el objetivo común de la felicidad personal. El conjunto de la información aislada de cada individuo serviría para identificar el motor común a toda acción particular. Este trabajo ya había sido realizado por Bentham y se resume en el principio de utilidad.

No hay, pues, hechos sociales, simplemente acciones individuales que deben promover la felicidad. Alcanzar la felicidad de los asociados, a partir de la información proporcionada por Bentham, sería la tarea de la sociedad -las leyes con que esta se organiza, y así a sus miembros habrán de prohibir lo que produzca dolor y promover lo que genere placer-. Tampoco hay principio de autoridad, todo debe ser probado por la experiencia y la buena lógica, nada más. Así las cosas,

24 “(...) los cuerpos existen y la extensión es una propiedad inherente en ellos, independiente de toda voluntad y de lo que digan los hombres” (Rojas, 1988, p. 342).

25 “(...) la bondad es propiedad inherente en algunos actos, y entre ellos en el de que se trata, independientemente de la voluntad y del dicho u opiniones de los hombres” (Rojas, 1988, p. 342).

26 Aquí se abre la posibilidad de una investigación sobre la naturaleza que se otorga al lenguaje en los trabajos de Rojas que podría explicar cómo dicha naturaleza es, a la vez, activa y pasiva, es decir, cómo el lenguaje pude ser, al mismo tiempo, un medio de expresión del material empírico en toda su pureza cuando se trata de la verdad, pero contaminante y deformador cuando se trata del error. 
además de conectar la política con la lógica y la moral, el punto de vista de Rojas le permite señalar un garante último de la acción y el conocimiento, un fondo común a estos ámbitos de la vida humana que se reduciría a la causalidad que funda el orden natural.

El reino de la causalidad es el reino de la universalidad que servirá como garante, no solo del conocimiento en general, sino de la ley humana ${ }^{27}$. La lógica solo ayudaría a dar cuenta de ese mundo a través de la deducción correcta. No parece haber más cuestiones en su trabajo: un mundo, un método, una lógica, una verdad. No obstante, por momentos, Rojas sorprende con resultados inesperados de sus análisis.

Cuando enfrenta una frase de Emilio Castelar que dice "La inteligencia que solo da de sí un corazón corrompido, es como la flor que da un fruto gusaniento"(Castellar, 1858, p. 41), y luego de un par de páginas donde despliega todo su arsenal analítico para probar que este sigue también un principio utilitarista (descomposición de las frases, redefinición de las metáforas en ideas precisas, analogías, resolución de preguntas a partir de la reformulación de las mismas y deducciones lógicas), Rojas dice que Castellar podría afirmar, cuando se trata de legislar,

(...) [Q]ue la dicha y prosperidad de su patria, o lo que es lo mismo, su bien general, es lo que se propone en todos sus actos, y que solo halla buenas las instituciones y leyes que lo producen; y malas las que lo contrarían: lo que quiere decir que la utilidad general es su lógica en legislación, es decir, su principio de razonamiento. (Rojas, 1988, p. 362)

Lo inesperado es el modo como iguala la noción de lógica a la de utilidad general. El uso epistemológico de la palabra cambia de ámbito para insertarse en una cuestión social relativa al principio de utilidad. No obstante, este giro deja de sorprender, o de generar quejas, si se tiene en cuenta que la experiencia es el camino que sigue una reflexión que encuentra en Bentham la piedra de toque. Los trabajos de este inglés le proporcionarían al moralista la posibilidad de hablar

27 Esta garantía de la ley es una de las cuestiones más importantes que se debatieron entre Ezequiel Rojas y Miguel Antonio Caro. Ambos tienen un grueso arsenal de argumentos acerca del origen de la ley, el papel de la historia y el lugar de la ciencia en la comprensión de ese origen y la correcta ejecución de la misma. Para ver los argumentos de Miguel Antonio Caro sobre esta cuestión véase el texto "Miguel Antonio Caro y el acto de escribir" (López J., 2008). 
científicamente de las acciones humanas: la economía política, una de las ciencias morales y políticas que, según Rojas, ha tenido éxito pues entendió que su base y fundamento "son las necesidades: si estas no existieran no existiría ciencia de las riquezas. -Pero las necesidades son sensaciones; luego la sensibilidad [como en la ciencia de la moral] es la base y fundamento de la ciencia de la economía política" (Rojas, 1988, p. 157) ${ }^{28}$.

Los desarrollos de la ciencia superan las limitaciones cognitivas de otros tiempos (como creer que las tiranías eran buenas formas de gobierno). Para ello, no obstante, habrán de sortearse los tres obstáculos mencionados atrás que conducen al error: la peculiaridad de los objetos de las ciencias morales y políticas obliga a tener paciencia para lograr la difícil observación de los fenómenos que le atañen. Respecto al método, la observación y la lógica honestamente ejercidos, garantizarán la verdad de los resultados. Por su parte, el nocivo efecto de los intereses particulares se contrarresta con la doble naturaleza que le asigna a la ciencia. Para entender esta última cuestión conviene reparar un momento en la finalidad que según Rojas tienen las ciencias morales y políticas:

Las acciones humanas se hallan en la misma condición que las cosas. Hay algunas que tienen propiedades que les son inherentes, y en virtud de ellas afectan a los hombres, haciéndoles mal, es decir, haciéndolos sufrir; y hay otras que tienen las de producir los efectos contrarios.

El conocimiento de las leyes de la naturaleza de las acciones humanas, y el de la constitución del hombre, son, pues, indispensables para proporcionarles el modo de ser a que aspiran. (Rojas, 1988, p. 66)

Las ciencias morales tendrían la misma finalidad del hombre, pero en el marco de la vida en sociedad. Las constantes analogías entre la medicina y la moral son un prueba de ello, a lo largo de todo el texto, Rojas compara su trabajo con el del médico, muestra que el buen funcionamiento de la sociedad es como el buen funcionamiento del cuerpo de cada uno de sus individuos, y por ello, la ciencia de los hechos relativos a las acciones humanas es de vital importancia para la vida de la sociedad en general.

28 La cuarta parte del primer tomo de las obras de Rojas editadas por Ángel María Galán se titula "Economía política o social". Igual que el título uno de los tantos programas de las clases que Rojas dictó y que se editaron en esta obra (Rojas, 1881, pp. 201-203). 
De allí que, apropósito del conocimiento de la moral y la política, Rojas (1988) afirme: "cuando las ciencias han llenado su objeto, haciendo conocer bien cuáles son las causas que producen mal y las que producen el bien, entonces es cuando pueden ser sancionadas leyes e instituciones que conduzcan a los hombres a su felicidad" (p. 108).

En esta cita la expresión "conducir" no aparece en vano, los hombres, al margen de las leyes e instituciones, no actúan siempre conforme a los resultados de la ciencia. Los tres obstáculos de los que ya se habló, impiden que esta ciencia se consolide. De allí que, en lo que las ciencias morales y políticas se perfeccionan, se requiera de la voluntad de los hombres para que en sociedad alcancen la felicidad: "inspirar e imprimir en los hombres esta voluntad, es el deber de cuantos tienen o toman la misión de gobernarlos y de dirigirlos, con cualquier carácter que sea. - La ciencia consiste, no en querer que se haga, SINO EN HACER QUE SE QUIERA [sic]" (Rojas, 1988, p. 149).

Esta labor de la ciencia, cada vez más fundamental, supone una última escalada. En el tránsito desde lo epistemológico hasta lo político, pasando por la ontología, la lógica y la moral, la ciencia adquiere un extraño estatuto: gracias ella harán buen cumplimiento del deber quienes eligen a sus gobernantes - "El deber de los electores es, pues, el de sufragar por personas que tengan la honradez y la ciencia necesarias para desempeñar bien y fielmente sus funciones" (Rojas, 1988, p. 206)-. Pero la adquisición de la "ciencia" también es un deber del gobernante, por eso, en el sexto punto de las garantías para que los gobernantes no abusen de su poder Rojas (1988) sostiene:

6. En que la delegación de su poder la hagan en personas que haya motivo fundado de esperar que tienen voluntad, conocimiento y medios de cumplir fielmente las obligaciones que contraen, es decir, en personas que tengan la honradez y la ciencia necesarias para desempeñar las funciones que se les encargan. (p. 208)

Apoyado en esta imagen del gobernante, uno que no solo tiene un conocimiento, sino que a través de él cumple adecuadamente sus tareas, Rojas (1988) se permite afirmar que:

(...) $[\mathrm{L}]$ os soberanos tienen derecho para establecer quiénes son los que deben sufragar y quiénes no: luego la función de sufragar solo debe conferirse a los que, por sus condiciones y circunstancias, den garantías de que elegirán 
personas de la honradez y ciencia necesarias para desempeñar dignamente los puestos que se les confían. (p. 207)

El modo de ser del mundo y sus atributos, las causas de ese modo de ser y el hombre como parte de las cosas en él, constituyen los elementos de una reflexión epistemológica que se mueve entre la ontología, la lógica, la moral y la política. Además, esta reflexión mezcla ámbitos que por lo común se presentan separados (aunque en la actualidad hablemos de relaciones saber-poder o de una estética que es política), acarrea una condición adicional y es el destacado papel que se le otorga a la ciencia en el cuerpo social, ella, indistintamente, se convierte en medio y fin del proyecto de Rojas; ella no solo es la manera a través de la cual se conoce la verdad, se orienta la conducta individual y se define al mejor gobernante, sino también aquello que ha de propagarse en el cuerpo social con el fin de que los posibles electores alcancen el mérito de ser considerados como tales.

\section{Conclusiones}

Como se mostró, a los ojos de Rojas la ciencia es la única forma posible de saber supone un mundo creado, unos seres fijos, directamente reconocibles por la sensación. A este conocimiento se accede a través del lenguaje, el cual se transforma en virtud de los resultados del método experimental y exige un trato moral definido por la lógica, que hacen posible la verdad. Para Rojas, además, la ciencia tiene finalidades sociales muy precisas, como generar armonía y felicidad. La ciencia, por último, llega hasta el gobierno democrático, pues en esta dimensión ella se porta como una virtud indispensable para electores y gobernantes.

El procedimiento con que se mostraron estas múltiples dimensiones de la ciencia en su obra filosófica consistió en no partir de definiciones de ciencia, sino en buscarlas en un enclave empírico de referencia (la obra de Ezequiel Rojas), es decir, en una materialidad concreta, la cual definimos trazando sus relaciones internas de tal manera que mostraran el lugar de un concepto preciso que permita a futuras investigaciones no solo definir la forma local del ejercicio de escritura, sino sus relaciones con espacios como el gobierno, la política o la práctica intelectual en sus diversos aspectos.

Este procedimiento básico consistió en revisar los giros argumentativos más comunes en los trabajos de Rojas, identificar el modo como conecta temas de 
diversa índole, buscar dentro de su obra las formas más razonables de entender lo que para otros es una contradicción, un síntoma de atraso intelectual, un conjunto de saltos lógicos y cambios arbitrarios de nivel análisis, o la evidencia de unas las tensiones no resueltas (antiguo/moderno, creacionismo/sensualismo ${ }^{29}$ ). Si bien se trata de un procedimiento de lectura convencional, el modo en que, por lo común, se usan estos documentos en diversas formas de narrar la historia de Colombia, incluso en la historia de la filosofía colombiana, insiste en verlos a la luz de factores exógenos a la obra misma. Así, como se mostró, volver sobre los escritos de Rojas abre las puertas a un conocimiento más detallado de su obra y de las discusiones por las que ella misma fue creciendo. Este conocimiento, entre otras cosas, ayudaría no solo en una historia de los modos de ser de la escritura, de los intelectuales y de sus prácticas, sino en la de unos lenguajes políticos y de la concepción misma del Estado.

Además, un análisis del ejercicio de escritura, en este caso de los textos filosóficos de Ezequiel Rojas, permitirá avanzar en la comprensión del significado efectivo de la noción filosofía en el actual territorio colombiano (pues más allá de las definiciones oficiales en las que la producción local siempre se presenta como insuficiente), y mostrar que en efecto hubo un uso de la noción que no solo se transformó con el tiempo de acuerdo con los debates y necesidades, sino que tuvo límites bien definidos y funciones sociales precisas, por ejemplo en la educación ${ }^{30}$. Aclarar este panorama permitirá también darle una dimensión intelectual a los debates sobre las escuelas de pensamiento que efectivamente tuvie-

29 "Rojas se cuidaba poco de las incongruencias y en este caso no percibía la contradicción entre afirmar que todo pensamiento tiene origen en la sensación y sostener que antes del desarrollo de la sensibilidad, tanto filogenética como ontogénicamente, tanto desde el punto de vista de la especie como del individuo, pudo existir una inteligencia y una fantasía que "poblaban el mundo de figuras brillantes y fantásticas". Aceptando una inteligencia y una fantasía anteriores a la sensación, y hasta un deseo innato de saber, Rojas aceptaba una concepción del espíritu humano no compatible con el sensualismo que coloca la sensación como punto de partida y origen de todas las manifestaciones psicológicas y espirituales" (Jaramillo Uribe, 1962, pp. 19-20).

30 Algunos aspectos del uso de la filosofía en la educación son estudiados por Oscar Saldarriaga Vélez en su artículo "De universidades a Colegios" (2008). En la actualidad, este autor avanza en el desarrollo de un proyecto de investigación titulado "Saberes y disciplinas escolares en Colombia". Concretamente desarrolla la línea "La filosofía como disciplina escolar" junto a Juan Manuel Dávila y Liliana Martínez. Algunos de los pasajes de este escrito fueron posibles gracias a la lectura de los resultados del proyecto mencionado, a la conversación de viva voz y a la interacción epistolar que generosamente Oscar y Liliana han mantenido conmigo los últimos años: muchas gracias a ambos. 
ron un impacto en lo que hoy llamamos Colombia, escuelas como el utilitarismo, el positivismo o el tradicionalismo y discusiones en torno a la orientación del Estado o al uso de la autoridad como fuente de legalidad (un tema central de las preocupaciones intelectuales de Rojas como de su gran opositor Miguel Antonio Caro); debates que requieren de análisis adicionales a la perspectiva partidista o a las luchas por el control del poder central.

Una ventaja adicional de este procedimiento consiste en que abre las puertas para generar claves de interpretación locales de la producción que se estudia. De un lado, se dependerá menos de la producción de categorías analíticas de Europa y EEUU; categorías que muchas veces no alcanzan a dar cuenta de los fenómenos que se analizan como bien lo mostró Germán Colmenares en su texto "Las convenciones contra la cultura”; sumado a esto, se podrán establecer condiciones de diálogo con menos mediaciones entre la producción intelectual de distintos lugares del planeta (al menos de Latinoamérica) por fuera los centros hegemónicos de producción de conocimiento. De otro lado, gana la posibilidad de ampliar el margen de lo que en filosofía se llama la tradición ${ }^{31}$, es decir, gana la posibilidad de que textos locales hagan parte de la misma sin complejos o advertencias sobre su calidad o limitaciones analíticas, y sirvan para pensar problemas del presente con las inquietudes que efectivamente se han pensado, en lugares como el actual territorio colombiano, desde hace bastante más de dos siglos.

Referencias

Colmenares, G. (1997). Las convenciones contra la cultura. Ensayos sobre historiografía hispanoamericana del siglo XIX. Bogotá: Tercer Mundo.

Jaramillo Uribe, J. (1962). Bentham y los utilitaristas colombianos del siglo XIX. Ideas y Valores, IV (13), pp. 11-28.

31 El tema de la ampliación de la tradición filosófica europea para aquellos que se dedican a la filosofía profesional no es nuevo en la historia de la filosofía colombiana, Jaime Jaramillo escribió en 1954 un breve texto titulado "Tradición y problemas de la filosofía en Colombia" (1968). Recientemente se publicó, a propósito del modo en que en Colombia se consolidó esa tradición profesional y las posibilidades de ampliar el canon filosófico europeo para el ejercicio local de la filosofía, el artículo titulado "Normalización de la filosofía y filosofía latinoamericana en Colombia" (López J., 2012). 
Jaramillo Uribe, J. (2001). El pensamiento colombiano en el siglo XIX. Bogotá: Alfaomega grupo editor.

Latour, B. (2001). La esperanza de Pandora. Barcelona: Gedisa.

López J., C.A. (2008). Miguel Antonio Caro y el acto de escribir. M. Domínguez Miranda (Ed.), Introducción a Miguel Antonio Caro (pp. 1-156). Bogotá: Instituto Pensar-Instituto Caro y Cuervo.

López J., C.A. (2011). Reseña: Prensa y tradición. La imagen de España en la obra de Miguel Antonio Caro. Universitas Philosophica, 28(56), pp. 271-278.

López J., C.A. (2012). Normalización de la filosofía y filosofía latinoamericana en Colombia. Viviencia de un proceso. Universitas Philosophica, 29(58), pp. 309-327.

López J., C.A. (2014). Gobiernos, modernidad y producción escrita en Colombia (1880-1930): La escritura como terreno común de los antagonismos. Desafios, 26(2), pp.43-71.

Martínez, R. (2014). La primera controversia sobre el utilitarismo en Colombia (1825-1836): disputas entre las élites por el control de los fundamentos filosóficos del derecho. Revista facultad de derecho y ciencias politicas, 121(44), pp. 721-766.

Múnera, A. (1998). El fracaso de la nación. Región, clase y raza en el Caribe Colombiano (1717-1810). Bogotá: Banco de la República-Áncora editores.

Quintana, L. (2006). Ezequiel Rojas y la moral utilitarista. R. Sierra Mejía (Ed.), El Radicalismo Colombiano en el siglo XIX (pp. 11-37). Bogotá: UNAL.

Rodríguez Valbuena, M.G. (2003). La filosofía en Colombia. Modernidad y conficto. Rosario: Laborde Editor.

Rojas, E. (1988). Escritos éticos. G. Marquínez Argote (Ed.). Bogotá: Biblioteca Colombiana de Filosofía.

Saldarriaga, O. (2004). Gramática, Epistemología y Pedagogía en el siglo XIX: la polémica colombiana sobre los elementos de ideología de Destutt De Tracy (1870). Memoria y sociedad, 8(17), pp. 41-59.

Saldarriaga, O. (2008). De universidades a colegios: la filosofía escolar y la conformación del bachillerato moderno en Colombia 1792-1892. S. CastroGómez \& E. Restrepo (Eds.), Genealogía de la colombianidad. Formaciones 
discursivas y tecnologias de gobierno en los siglos XIX y XX (pp. 308-333). Bogotá: Editorial Pontificia Universidad Javeriana-Pensar.

Valderrama Andrade, C. (1961). Elpensamiento filosófico de Miguel Antonio Caro. Bogotá: Instituto Caro y Cuervo.

Valderrama Andrade, C. (1989). Relación polémica de Miguel Antonio Caro con el benthamismo. Ideas y Valores, 38(80), pp. 121-144. 